\title{
DIAKRONIKA
}

Vol. 17 No. 1 Th. 2017 p: 34-45

ISSN: 1411-1764 (Print) | 2620-9446 (Online)

http://diakronika.ppj.unp.ac.id

\section{Kebijakan Politik Pendidikan Tinggi Pemerintah Kolonial Belandadi Indonesia (1920-1942)}

\author{
Hendri \\ minangkabauuniversity@yahoo.com \\ Dinas Pendidikan Provinsi Sumatera Barat
}

\begin{abstract}
The history of higher education in the Republic of Indonesia primarily on August 19, 1945, that was the founded of Balai Perguruan Tinggi Republik Indonesia(BPTRI) in Jakarta, upstairs of personage Indonesian higher education. However, if we look back as a long time, before freedom of Indonesian (August 17, 1945), actually the higher education in Indonesia had been founded, even had formed of system's based on religions (Buddha, Islam, and Christian). Islamic people had founded institutes of Islamic education, for example Surau, Pesantren, Madrasah, etc, as well as with Christian that brought of colonialist (Dutch) to Indonesia. Dutch colonialist founding and make reorganizing to higher education them star at 1920-1942. They did it because certaint reasons, priority to fuulfil they need of their colonialism and they economic's advantages from Indonesia. The higher education had they founded are THS te Bandoeng (1920), RHS te Batavia (1924), GHS te Batavia (1927), FLeW Batavia (1940), dan FvLw Buitenzorg (1941). At Republik Indonesia Serikat (1950's), this higher education to be formed faculties of Universiteit Indonesia/BPTRIS.
\end{abstract}

Keywords: cause's of policy, higher education politic, dutch colonial government in Indonesia.

\begin{abstract}
Abstrak
Sejarah tentang pendidikan Tinggi Republik Indonesia dimulai sejak 19 Agustus 1945, yaitu didirikan oleh Balai Perguruan Tinggi Republik Indonesia (BPTRI) di Jakarta, mengenai pendidikan Tinggi di Indonesia. Jika dilihat kembali sebelum kemerdekaan Indonesia (17 Agustus 1945), sebenarnya pendidikan tinggi di Indonesia telah terbentuk dan sudah memiliki sistem berbasis agama Budha, islam Kristen. Orangorang islam telah mendirikan lembaga pendidikan islam contohnya, surau, madrasah, pesantren dan lain-lain. Begtu juga dengan kaum kristianai yangn dibawa oleh kolonial ke Indonesia. Penjajah belanda mendirikan dan membuat reorganisasi ke pendidikan yang lebih tinggi pada tahun 1920-1942. Mereka melakukan itu karena untuk memenuhi kebutuhan yang mereka butuhkan terutama keuntungan ekonomi di Indonesia. Pendidikan tinggi yang mereka dirikan diantaranya THS te Bandoeng (1920), RHS te Batavia (1924), GHS te Batavia (1927), FleW Batavia (1940) dan FVLw Buitenzory (1941). Di republik Indonesia serikat (1950-an) pendidian tinggi ini berbentuk fakultas, Universitet Indonesia/ BPTRIS.
\end{abstract}

Kata Kunci: peraturan, pendidikan tinggi, pemerintahan kolonial Belanda 


\section{Pendahuluan}

Jika ditinjau dari masa setelah proklamasi kemerdekaan (17 Agustus 1945), berdirinya pendidikan tinggi di Republik Indonesia merdeka belum lama. Tradisi pendidikan tinggi yang berkembang di negara RI berawal dari Pemerintahan Koloniala Belanda, melalui penggabungan Universiteit van Indonesië (UVI)(S. Somadikarta, 2015), dengan Balai Perguruan Tinggi Republik Indonesia (BPTRI) (Irsyam, Oemaryati, \& Somadikarta, 2000) maka berdirilah Universitet Indonesia/Balai Perguruan Tinggi Republik Indonesia Serikat (BPTRI). Dari Universitet Indonesia/BPTRIS kemudian menjadi sebuah Universitas Indonesia atau yang sering dikenal dengan nama UI. Perubahan perkembangan UI terjadi pada 1950-1998 akhirnya beberapa universitas/institute yang berpengaruh dan terkenal di Indonesia. Periode (1950-1998), terjadi perubahan yang mendasar di tubuh UI yaitu (1) pembukaan 15 fakultas baru (Irsyam et al., 2000), (2) pengubahan nama lima fakultas (Irsyam et al., 2000), dan (3) pengalihan 11 fakultas dan tiga lembaga kepada tujuh pendidikan (universitas, institut, dan politeknik) yang baru didirikan pada saat itu.

Tahun 1959-1966, pemerintah RI telah mendirikan 29 Perguruan Tinggi Negeri (PTN) yang terbagi dalam 2 kategori. Pertama, perguruan tinggi yang sama sekali baru, artinya pada mulanya belum ada PTN di daerah tersebut. Dalam kategori ini termasuk pula PTN yang pada mulanya merupakan perguruan tinggi swasta. Kedua, perguruan tinggi yang pada mulanya merupakan bagian dari suatu PTN. Misalnya ITB dan IPB merupakan perguruan tinggi yang termasuk dalam kategori kedua ini karena kedua perguruan tinggi tersebut dari Fakultas Teknik UI di Bandung dan Fakultas Pertanian \& Kehewanan UI di Bogor. Artinya ITB dan IPB adalah cabang dari UI.

Secara historis, IKIP Jakarta merupakan Fakultas Pedagogik UI dan IKIP Yogyakarta semula Fakultas Pedagogik UGM (Irsyam et al., 2000). Sedangkan UNP yang berasal dari PTPG Batusangkar. Dalam perjalanan sejarahnya pernah digabungkan ke Universitas Andalas (UNAND, 1956-1958), dan ke IKIP Jakarta Cabang Padang (1964-1965), dimana pada periode ini IKIP Jakarta Cabang Padang mempunyai lima fakultas sehingga memenuhi syarat untuk menjadi IKIP yang berdiri sendiri. Ketiga IKIP menjadi sangat terkenal, terutama setelah menjadi universitas yaitu UNJ (Jakarta), UNY (Yogyakarta), dan UNP (Padang).

Berbagai kebijakan di bidang Pendidikan Tinggi pernah diterapkan pemerintah Kolonial Belanda di wilayah Indonesia pada tahun 1920-1942. Perubahan kebijakan tersebut dilakukan karena sebab-sebab tertentu, misalnya, politik etis/etische politiek (1901) dimana kolonial Belanda 
berpandangan b'ahwa Belanda harus membayar lunas hutang budi (een eereschuld) kepada bangsa Indonesia sebagai bangsa jajahannya (van Neil, 1984). Bangsa Indonesia memberikan keuntungan ekonomi yang sangat besar terhadap rakyat, negeri, dan Kerajaan Belanda dengan menggunakan sistem tanam paksa (cultuurstelse) yang diterapkan pada masa liberal (1863-1900) (Kartodirdjo, 1999).

Mempelajari perubahan yang kebijakan pada PT oleh pemerintah Kolonial Belanda, diketahui bahwa ada beberapa lembaga pendidikan tinggi, telah didirikan oleh pemerintah Kolonial Belanda di Indonesia, sebelum didirikan Universitet Indonesia/BPTRIS (Irsyam et al., 2000). Hal seperti ini juga dikemukakan oleh Sirozi (2004) bahwa pada tahun 1939 hanya ada delapan lembaga pendidikan tinggi di Indonesia, tujuh di antaranya terletak di pulau Jawa (Sirozi, 2004). Lembaga pendidikan tinggi tersebut adalah Technische Hoogesschool te Bandoeng (1920), Rechtshoogeschool te Batavia (1924), Geneeskundinge Hoogeschool te Batavia (1927), Faculteit der Lettern en Wijsbegeerte Batavia (1940), dan Faculteit van Landbouwwetenschap Buitenzorg (1941) (Irsyam et al., 2000). Saat Pemerintah Kolonial Belanda mendirikan dan mengadakan perubahan terhadap pendidikan tinggi disebabkan hal-hal tertentu. Peneliti juga mengkaji masalah Pemerintah Kolonial Belanda dalam mendirikan dan melakukan perubahan kebijakan terhadap pendidikan tinggi? ada dua masalah yang dikaji dalam penelitian ini; Pertama, mengapa pemerintah Kolonial Belanda mendirikan serta mengadakan berbagai perubahan terhadap Pendidikan Tinggi Indonesia sejak tahun 1920-1942? Kedua, apa, dimana, kapan, siapa, mengapa, dan bagaimanakah sejarah Pendidikan Tinggi yang didirikan oleh Pemerintah Kolonial Belanda di Indonesia tahun 1920-1942 tersebut?

Teori yang dipakai membahas Kebijakan Politik Pendidikan Tinggi Pemerintah Kolonial Belanda di Indonesia (1920-1942) adalah teori Kolonialisme sebagaimana yang dikemukakan oleh Dadang Supardan:

Imperealisme dalam ekspansi bangsa-bangsa Eropa Barat ke berbagai wilayah lainnya di dunia sejak abad ke-15 dan 16 pada puncak perkembangan, kolonialisme merajalela pada abad ke-19, dimana hampir setiap negara Eropa memiliki daerah jajahan di Asia, Afrika, dan Amerika. Kolonialisme bermula sejak serangkaian petualangan yang liar mencari kekayaan, kejayaan, dan menyebar agama (gold, glory, end gospel). Awal Kedaulatan wilayah seberang diambilalih, baik melalui paksaan militer maupun tindakan licik lainnya (Denon-Birot, 2000). Kalau penguasa tingkat lokal masih bertahan, kekuasaann riilnya sudah jauh berkurang atau bahkan lenyap sama sekali. Begitu pula ketika 
kekuasaan Kolonial makin kuat, mereka bertindak makin mencampuri kehidupan sehari-hari dalam dominasi politik, eksploitasi ekonomi, maupun panetrasi budaya. Pada tahap gilirannya, tindakan akan menimbulkan perlawanan sehingga sekaligus mengawali transfer bertahap dari kekuasaan Kolonial ke pemimpin nasionalis yang heroic (Supardan, Hasan, \& Rachmatika, 2008).

Djoko Surjo menjelaskan bahwa:

Pada awal kehadiran orang-orang Belanda di kepulauan Indonesia karena kepentingan ekonomi untuk mengejar keuntungan berawal kegiatan perdagangan. Masa berikutnya motivasi tersebut bergeser ke motivasi kepentingan politik ekspansi sistem kekuasaan, Kolonialisme, Imperealisme untuks kepentingan negeri Belanda (Surjo, 2012).

Perubahan mulai terjadi setelah VOC di Indonesia bangkrut (16021799) dan wilayah pengaruhnya di kepulauan Indonesia diambil-alih oleh Kerajaan Belanda. Kerajaan Belanda kemudian mendirikan pemerintahan Kolonial Belanda di Indonesia (1817) sebagai perpanjangan tangan dari pemerintah Kerajaan Belanda di Eropa. Sejak itu (1817), Indonesia menjadi tanah jajahan Belanda. Akibat dari perpanjangan kekuasaan Kerajaan Belanda di Indonesia, maka sistem politik, pemerintahan, hukum, sosial, ekonomi, pendidikan, dan kebudayaan Indonesia secara sentral dikendalikan oleh Kerajaan Belanda melalui pejabat yang ditunjuk untuk Indonesia yaitu Gubernur Jenderal Hindia Belanda. Gubernur Jenderal ini berkedudukan di Batavia yang menjadi lbukota negara, sekaligus menjadi pusat pemerintahan. Dari Batavia berbagai kebijakan dari Pemerintah Kolonial Belanda yang Sdilancarkan keseluruh wilayah Indonesia.

Teori Kolonialisme Belanda dalam kerangka kebijakan politik pendidikan tinggi ini ditopang oleh beberapa konsep yaitu pertama, konsep kebijakan politik Pemerintah Kolonial Belanda di Indonesia. Kedua, konsep politik pendidikan tinggi Pemerintah Kolonial Belanda di Indonesia. Ketiga, konsep sebab-akibat Pemerintah Kolonial Belanda mendirikan pendidikan tinggi wilayah Indonesia. Keempat, Tentangkonsep perubahan terhadap bidang pendidikan menengah menjadi pendidikan tinggi, dan kelima, konsep ruang dan konsep waktu Kolonisasi (proses penjajahan) Belanda di Indonesia (1920-1942). 


\section{Metode}

Sesuai dengan rumusan jenis masalah dan fokus penelitian, maka dalam penelitian penelitian kualitatif dengan mengunakan metode penelitian sejarah. Metode penelitian sejarah mencakup empat tahap yaitu (1) Heuristik, (2) Kritik sumber, (3) Interpretasi, dan (4) Historiografi.

Teknik dan alat pengumpul data penelitian menggunakan strategi dan langkah-langkah riset kepustakaan (Mestika Zed, 2004:81). Sedangkan peneliti adalah sebagai alat pengumpul data penelitian. Data primer adalah sumber dari tangan pertama, sumber tertulis yang dibuat oleh pelaku sejarah, orang yang terlibat, dan saksi mata. Sumber primer dalam penelitian adalah Regeringreglement, Verslag, Veslagen, Statueten, Archief, dsb. Data sekunder adalah sumber data dari tangan kedua, hasil interpretasi terhadap sumbersumber primer, dan karya-karya sejarah yang ditulis oleh Sejarawan (berupa buku, essai, jurnal, dsb). Penelitian kepustakaan (library research) membatasi kegiatannya pada bahan-bahan koleksi perpustakaan saja tanpa memerlukan riset lapangan.

\section{Pembahasan}

Mr. Conrad Theodore van Deventer menulis sebuah karangan dalam majalah De Gids yang berjudul "hutang kehormatan" pada tahun 1899, "bahwa dari hasil panen yang sangat berharga melalui sistem tanam paksa di Indonesia, negeri, rakyat, dan Kerajaan Belanda telah memperoleh keuntungan berjuta-juta Gulden dari rakyat Indonesia." Hal itu merupakan hutang negeri Belanda terhadap rakyat Indonesia yang harus dikembalikan, sekalipun dalam bentuk lain. Sehingga pada tahun 1901-1942, kebijakankebijakan oleh pemerintah Kolonial Belanda di Indonesia berdasarkan pada kebijakan Poltik Etis yang telah ditetapkan Ratu Belanda sejak 1901, melalui pidatonya di Staaten Generaal.

Politik Etis berakar pada dua hal yaitu masalah humanitas dan keuntungan ekonomi. Politik Etis berhasil mencapai kesuksesan berkat keuntungan yang diberikan politik tersebut untuk memenuhi kebutuhan perusahaan dibiayai oleh modal besar, penanaman modal, dan pendirian Bank yang dapat berkembang pesat. Pemerintah Kolonial Belanda, pihak swasta (perkebunan dan perusahaan besar) di daerah Hindia Belanda yang sangat memerlukan pegawai terdidik dan politik etis serasi bagi tujuan itu ( $S$ Nasution, 2001).

Politik Etis pada prinsipnya hanya slogan indah untuk menutupi metode eksploitasi modal raksasa kolonial Belanda/Eropa di Indonesia. Perorangan dari tokoh Politik Etis tersebut sudah bersikap etis terhadap rakyat pribumi, akan tetapi perusahaan Belanda/Eropa yang bertindak tidak 
berdasarkan Politik Etis, melainkan karena kepentingan ekonomi. Oleh sebab itu para pemilik modal sangat mendukung didirikannya Pendidikan Tinggi untuk menghasilkan tenaga kerja/pegawai agar mudah didapatkan dengan upah rendah, supaya menjamin keuntungan maksimal bagi para pemilik modal Belanda.

Faktor internal dan eksternal yang mempengaruhi terbagi atas tiga. Pertama, sebab yang terdapat di negeri Belanda antara lain:

a) Pergantian/suksesi kepemimpinan politik yang terjadi di negeri Belanda yaitu dari ideologi liberal (1817-1900) ke ideologi politik etis (1901-1942).

b) Kebijakan politik pemerintah Kerajaan Belanda + Staaten Generaal untuk melaksanakan politik etis di Indonesia sebagai tanah jajahannya tahun 1901-1942.

c) Banyaknya pengusaha swasta Kolonial Belanda/Eropa yang menanamkan modal di Indonesia (bidang perkebunan, pertanian, pertambangan), mereka juga ikut mempengaruhi, merencanakan, dan mendukung dilaksanakannya kebijakan politik pendidikan tinggi Pemerintah Kolonial di Indonesia.

d) Negeri Belanda diduduki oleh Jerman pada PD II (10 Mei 1940).

Kedua, sebab yang terdapat di Indonesia (Hindia Belanda) antara lain:

a) Kebijakan politik pendidikan tinggi Pemerintah Kolonial Belanda di Indonesia adalah "alat" untuk menghambat pergerakan nasional kebangsaan Indonesia untuk memperjuangkan kemerdekaan Indonesia.

b) Untuk menghambat munculnya perguruan swasta yang militan (memperjuangkan kemerdekaan Indonesia) Taman Siswa dan INS Kayutanam di Minangkabau.

Ketiga, sebab lain jika dikaitkan dengan kondisi dunia pada waktu itu yaitu tahun 1920-1942.

a) Terjadinya PD I (1914-1918) di Eropa, negeri Belanda diduduki oleh Jerman sehingga terhalang pengiriman dari tenaga kerja terdidik/pegawai Belanda yang akan bekerja di Indonesia tahun 1920-an.

b) Krisis ekonomi dunia yang sangat parah melanda semua negara-negara di dunia pada tahun 1930-an.

c) Belanda diduduki oleh Jerman pada PD II (10 Mei 1940), sehingga Kolonial Belanda di Indonesia harus mendidik anak pribumi Indonesia untuk menjadi pengawai agar aktivitas ekonomi Belanda di wilayah Indonesia dapat berjalan. 
Pemerintah Kolonial Belanda mendirikan pendidikan tinggi dengan cara mengadakan perubahan terhadap:

1. Onderwijs van Inlandsche ëleves voor de Geneeskunde en vaccine (1849), $\rightarrow$ Dokterdjawaschool Batavia (DJS Batavia, 1853), $\rightarrow$ School tot Opleiding voor Inlandsch Geneeskundig Batavia (STOVIG Batavia,1888), $\rightarrow$ School tot Opleiding voor Indisch Artsen Batavia (STOVIA Batavia,1898), $\rightarrow$ Geneeskundige Hogeschool te Batavia (GHS te Batavia, 1927).

2. Sekolah Khusus Anak Raja-raja (1893), $\rightarrow$ Sekolah Calon Pejabat Pribumi yaitu Hoofdenschool (1900), $\rightarrow$ Opleiding School voor Inlandsch Rectkundinge Batavia (OSVIR Batavia,1909-1929), $\rightarrow$ Rechtsschool Batavia (RS Batavia,1922-1924), $\rightarrow$ Rechtshogesschool te Batavia (RHS te Batavia, 1924-1942).

3. Technische Hogeschool te Bandoeng (THS te Bandoeng,1920).

4. Facaulteit der Lettern en Wijsbegeerte te Batavia (FLeW Batavia,1940).

5. Faculteit van Landbouwwetenschaap Buitenzorg (FvLw Buitenzorg1941).

Kebijakan politik pendidikan tinggi yang dijalankan pemerintah kolonial Hindia Belanda di Indonesia adalah berdasarkan Hooger Onderwijs Wet 1905 dan Hooger Onderwijs Wet 1924 Ordonnantie (Undang-undang Pendidikan Tinggi 1905 dan 1924). Hooger Onderwijs Wet 1905 menetapkan perbedaan pendidikan tinggi (hooger onderwijs) dengan universitas (universiteit) serta syarat-syarat sebuah universitas yaitu harus memiliki lima fakultas (F. Teologi, F. Hukum, F. Kedokteran, F. Matematika dan Ilmu Alam, serta F. Sastra, filsafat). Sedangkan Hooger Onderwijs Wet 1924 Ordonnantie mengatur tentang pengambil-alihan THS te Bandoeng dari pihak swasta (KIVHTONI) pemerintah Kolonial Belanda dan menjadi dasar hukum pembukaan RHS te Batavia pada tahun 1924.

Kolonial Hindia Belanda sudah merencanakan untuk mendirikan sebuah universitas (Universiteit van Nederlandsch Indie) sebelum PD II (1938an), tetapi karena pecahnya perang Pasifik, kemudian Belanda menyerah tanpa syarat kepada Jepang (12 Maret 1942).

Terdapat istilah dalam Pendidikan Tinggi seperti President der Universiteit. Rector-Magnificus (Rektor), Voorzitter (Ketua Fakultas), Lector (Dosen), Curratourium (Majelis Wali/MWA seperti yang ada di UI dan ITB saat ini). Hoogeschool untuk(Sekolah Tinggi), Faculteit untuk(Fakultas), Instituut (Institut), Universiteit (Universitas), Hooger Onderwijs untuk(Pendidikan Tinggi), dan Ujian (examen). 
Ruang dan waktu Belanda mendirikan Pendidikan Tinggi yaitu dalam ruang-tempat wilayah Indonesia dan dalam rentang waktu tahun 1920-Maret 1942.

Syarat mendirikan Pendidikan Tinggi ditetapkan sebagaimana yang dijelaskan (Irsyam et al., 2000):

...berdasarkan Hooger Onderwijs Wet yang dimuat dalam Staatblad Koninkrijk der Nederlanden No. 181 Pasal 76, yaitusuatu universitas harus memiliki lima fakultas, yaitu 1) Faculteit der godgedeerbeid (Fakultas Teologi), 2) Faculteit Rechtkunderdbeid (Fakultas Hukum), 3) Faculteit der Geneeskunde untuk(Fakultas Kedokteran), 4) Faculteit der Art en Natuurkunde (Fakultas Matematika dan IImu Alam), dan 5)Faculteit der Lettern en Wijsbegeerte (Fakultas Sastra dan Filsafat)...

Tujuan Belanda mendirikan Pendidikan Tinggi adalah; (1) Tujuan utama Pemerintah Kolonial Belanda mendirikan Sekolah Tinggi bukanlah untuk inlanderstetapi karena desakan politik etis untuk dijalankan di PT tanah jajahan (Indonesia). (2) Tidak dimaksudkan untuk mencerdaskan orang Indonesia, melainkan tak lebih daripada sekedar memberi kesempatan kepada keluarga golongan tertentu yang dipercaya oleh Belanda untuk ikut mempertahankan kelangsungan penjajahan Belanda. (3) Mencetak tenaga kerja/pegawai yang bekerja diberbagai perkebunan/pabrik yang didirikan oleh pemilik modal swasta Belanda/Eropa di Indonesia. (4) Terhalangnya lulusan HBS di Indonesia melanjutkan pendidikan ke Universitas di Belanda, sehingga mendirikan perguruan tinggi di Indonesia menjadi solusi yang sangat penting.

Bentuk-bentuk di Pendidikan Tinggi yang didirikan oleh Pemerintah Kolonial Belanda adalah;

(1) Technische Hoogeschool te Bandoeng (THS te Bandoeng, 3 Juli 1920).

(2) Rechtshoogeschool te Batavia (RHS te Batavia, 28 Oktober 1924)

(3) Geneeskundige Hoogeschool te Batavia (GHS te Batavia, 16 Agustus 1927).

(4) Facaulteit der Lettern en Wijsbegeerte Batavia (FLeW Batavia, 1 Oktober 1940).

(5) Faculteit van Landbouwwetenschaap Buitenzorg (FvLw Buitenzorg, 1 September 1941). 
Gambar berikut ini merupakan Sistem Persekolahan Pemerintah Kolonial Hindia Belanda di Indonesia mulai tahun 1817 s/d Maret 1942.

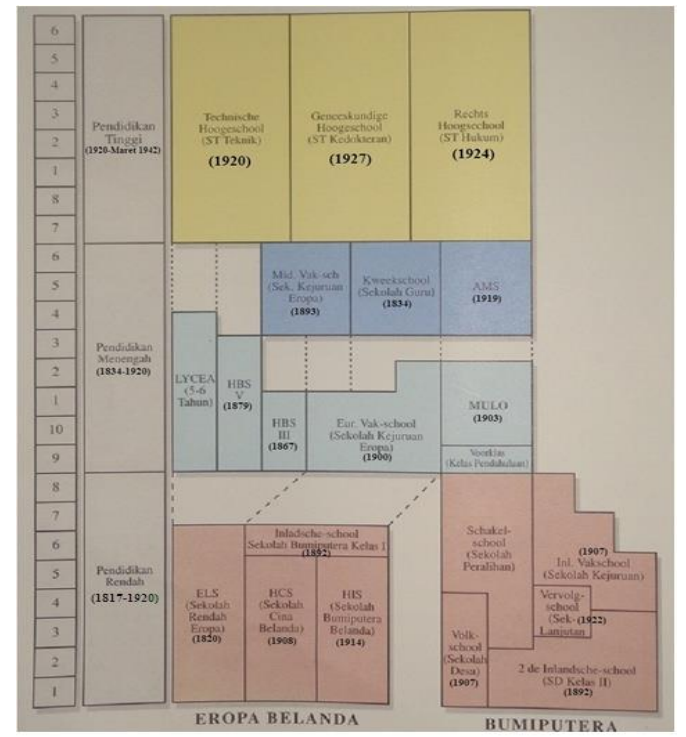

Gambar 1

Sumber: Djojonegoro (1996)

Terdiri atas dua bagian, pertama, sebab-sebab umum adalah;

(1) Pemerintah kolonial Hindia Belanda mendirikan Departemen Pendidikan, Agama, dan Industri (DVOEN) melalui departmen ini mereka telah mendirikan sekolah menengah, seperti yang dikenal(Ambachtsschool, Kweekschool, STOVIA Batavia, dan Hoofdenschool) yang menghasilkan pegawai terdidik bangsa pribumi Indonesia yang dapat menyokong kepentingannya dalam menjajah Indonesia.

(2) Masalah pendidikan dan kesehatan masyarakat pribumi Indonesia sangat berkembang (1910-1920), Belanda semakin membutuhkan pegawai sipil dari bangsa pribumi yang terdidik.

Sebab-sebab khusus adalah;

(1) Didirikan Indische Universiteits Vereeniging (1910) itu bertujuan mendirikan universitas di dalam wilayah Indonesia.

(2) Kolonial Belanda membentuk Commitë Indië Weerbaar (1917) yaitu komite bersama pertahanan Indonesia.

(3) Para pengusaha kolonial Belanda (1917) mendirikan KIVHTON/ bertujuan mendirikan pendidikan tinggi teknik di Indonesia.

(4) Dr. Abdul Rivai (1918) bersama 14 anggota Volkraad lain mengusulkan pembentukan suatu universitas di Indonesia. 
(5) Kebutuhan kolonial Belanda terhadap Insinyur (1919) semakin tinggi terutama untuk membangun jalan, jembatan, dan irigasi di Indonesia untuk tanah jajahannya.

(6) Terputusnya hubungan Indonesia-Belanda karena PD I (1914-1918) dan PD II (1938-1942).

(7) Negeri Belanda diduduki Jerman pada PD II (10 Mei 1940), dan lain-lain.

Hooger Onderwijs Wet 1905 yang dikeluarkan Ratu Wilhelmina berisi tentang ketetapan syarat-syarat universiteit sebagai pendidikan tinggi yaitu harus memiliki lima fakultas. Pada tahun 1910, muncul pikiran mengenai pendidikan tinggi di Indonesia oleh perkumpulan Hindia Belanda dari Den Haaq, pada tahun itu juga didirikan Indische Universiteit Vereeniging (IUV) di Den Haaq. IUV ini bertujuan untuk mendirikan pendidikan tinggi di Indonesia. Inisiatif ini mula-mula timbul dari orang Indo-Eropa, kemudian didukung oleh orang Indonesia pengikut Mr. Conrad Theodore van Deventer (etische koers).

Perkembangan selanjutnya, Mei 1917 beberapa orang pengusaha swastadari Belanda mendirikan KIVHTONI di Amsterdam. Mereka “menyumbangkan" Polytechnischool ke Indonesia, dalam kenyataannya tanggal 3 Juli 1920, KIVHTONI mendirikan THS te Bandoeng. Hal ini dilakukan Kolonial Belanda dalam kerangka kebijakan politik etis, khusus kebijakan politik pendidikan tinggi di Indonesia. Selain mendirikan THS te Bandoeng, pemerintah Kolonial Belanda juga mendirikan RHS te Batavia (1924) yang berasal dari perubahan terhadap RS Batavia tahun 1909, bertujuan untuk mendidik ahli hukum bumiputera (Mr.). Pemerintah kolonial Hindia Belanda juga melakukan hal yang sama terhadap STOVIA Batavia (1889) yaitu dengan mengadakan perubahan menjadi GHS te Batavia (1927).

Pada saat berkecamuknya PD II ( \pm 1938$)$, pemerintah kolonial Hindia Belanda takut akan kedatangan Jepang yang akan mengantikan penjajahannya terhadap Indonesia, para kolonialis Belanda berusaha "mengambil hati" bangsa Indonesia mendirikan FLeW te Batavia (1940) dan FvLw Buitenzorg (1941). Tujuannya bangsa Indonesia tetap memihak dan mendukung Belanda, serta melawan Jepang yang akan masuk. Walaupun pada tahun 1938-an, konsep Universitet Van Nederlandsch-Indie (UVNI) telah ada, namun adanya sebuah universitas di Indonesia selama penjajahan Belanda (1920-1942) tidak pernah terwujud.

Analisis Temuan Penelitian, Sebab-sebab diterapkannya kebijakan Politik Pendidikan Tinggi Pemerintah kolonial Hindia Belanda di Indonesia (1920-1942) adalah:

(1). "Sebagai Alat Politik kolonial Belanda" dalam menjalankan pemerintahan kolonialisme di Indonesia. 
(2). "Sebagai Inti dari Politik Kolonial Belanda" dalam upaya "menjaga, mempertahankan, mewariskan" kekuasaan penjajah di Indonesia.

(3). "Sebagai salah satu terjemahan kebijakan Politik Etis" yang telah mereka rancang dan siapkan untuk dijalankan di Indonesia sebagai tanah jajahannya.

(4). "Sebagai sebuah Pilihan Politik Pendidikan Kolonial Belanda" dalam rangka tetap terus menjajah dan mendapatkan keuntungan ekonomi dari Indonesia.

(5). "Sebagai solusi yang tepat bagi kaum kolonialis Belanda dalam menyesuaikan diri terhadap hukum alam yaitu letak negeri Belanda yang jauh dari Indonesia" (1920-Maret 1942).

(6). "Lembaga tempat berlangsungnya proses asosiasi kebudayaan Belanda dengan Indonesia" dalam menciptakan negara Belanda Raya (Belanda,Indonesia,Guyana/Cura ao, dan Suriname) tahun 1920-Maret 1942.

(7). "Sebagai Strategi menghancurkan perjuangan umat Islam Indonesia, yang sedang berjuang mencapai Kemerdekaan Indonesia (1920-Maret 1942)".

\section{Simpulan}

Pemerintah Kolonial Belanda ingin memperoleh pegawai sipil pribumi yang terdidik, untuk itu mereka mendirikan DVOEN yaitu Departmen Pendidikan, Agama, dan Industri. Melalui DVOEN, pemerintah mendirikan Sekolah Menengah (Ambachtschool, Hollandsch Inlandsch Kweekschool, STOVIA Batavia, dan Hoofdenschool). Pada tahun 1920, kolonial Belanda melalui KIVHTONI mendirikan THS te Bandoeng. Selain itu, rencana Belanda mendirikan UVNI (1938) dalam rangka "mengambil hati” bangsa Indonesia agar tetap memihak/membela Belanda di negara Indonesia, serta melawan Jepang yang akan masuk. Sehingga untuk bisa mewujudkan UVNI, harus memenuhi sebuah universitas yaitu memiliki lima fakultas. THS te Bandoeng (1920), RHS te Batavia (1924), dan GHS te Batavia (1927) didirikan. Kemudian Belanda mendirikan FLeW Batavia (1940) dan FvLw Buitenzorg (1942). Namun sampai Belanda menyerah tanpa syarat kepada Jepang (12 Maret 1942), UVNI direncanakan Belanda tidak pernah terwujud. Belanda telah terlambat dalam segala hal dan sangat tertinggal dibanding penjajah lainnya seperti Sanyol dan Inggris. 


\section{Daftar Rujukan}

Denon-Birot, M.-N. (2000). De la démocratie chrétienne à Force démocrate: échos d'une mutation politique. Editions L'Harmattan.

Djojonegoro, W. (1996). Lima puluh tahun perkembangan pendidikan Indonesia. Jakarta: Departemen Pendidikan dan Kebudayaan.

Irsyam, T. W. M., Oemaryati, B. S., \& Somadikarta, S. (2000). Tahun emas Universitas Indonesia. Jakarta: Universitas Indonesia (UI-Press).

Kartodirdjo, S. (1999). Pengantar Ilmu Sejarah Indonesia Baru: Sejarah Pergerakan Nasional dari Kolonialisme sampai Nasionalisme Jilid II. Jakarta: Gramedia Pustaka Utama.

S. Somadikarta. (2015). Menetapkan Tanggal Kelahiran Cikal-bakal Universitas Indonesia. Jakarta: Ul-Press.

S Nasution. (2001). Sejarah Pendidikan Indonesia. Jakarta: Bumi Aksara.

Sirozi, M. (2004). Politik Pendidikan di Indonesia: Peran Tokoh-tokoh Islam dalam Penyusunan UU No. 2/1989, diterjemahkan oleh Lilian D. Jakarta: INIS.

Supardan, H. D., Hasan, H., \& Rachmatika, R. (2008). Pengantar ilmu sosial: Sebuah kajian pendekatan struktural. Jakarta: Bumi Aksara.

Surjo, D. (2012). Indonesia dalam Arus Sejarah: Kolonisasi dan Perlawanan. Jakarta: PT. Ichtiar Baru van Hoeve bekerjsama dengan Kementerian Pendidikan dan Kebudayaan RI.

van Neil, R. (1984). Munculnya Elit Modern Indonesia, terjemahan. Pustaka Jaya. Jakarta. 